\title{
Characterization of unknown iodinated disinfection byproducts during chlorination/chloramination using ultrahigh resolution mass spectrometry
}

\author{
Xin Wang ${ }^{\mathrm{a}}$, Juan Wang ${ }^{\mathrm{a}}$, Yahe Zhang ${ }^{\mathrm{b}}$, Quan Shi ${ }^{\mathrm{b}}$, Haifeng Zhang ${ }^{\mathrm{a}}$, Yu Zhang ${ }^{\mathrm{a}}$, Min Yang ${ }^{\mathrm{a}, *}$ \\ a State Key Laboratory of Environmental Aquatic Chemistry, Research Center for Eco-Environmental Sciences, Chinese Academy of Sciences, Beijing 100085, China \\ b State Key Laboratory of Heavy Oil Processing, China University of Petroleum, Beijing 102249, China
}

\section{H I G H L I G H T S}

- The formulas of 206 iodinated DBPs in chloraminated drinking water were proposed.

- More than $68 \%$ of the I-DBPs might have aromatic or polycyclic aromatic structures.

- Precursors with high aromaticity is preferential to form iodinated DBPs.

\section{G R A P H I C A L A B S T R A C T}

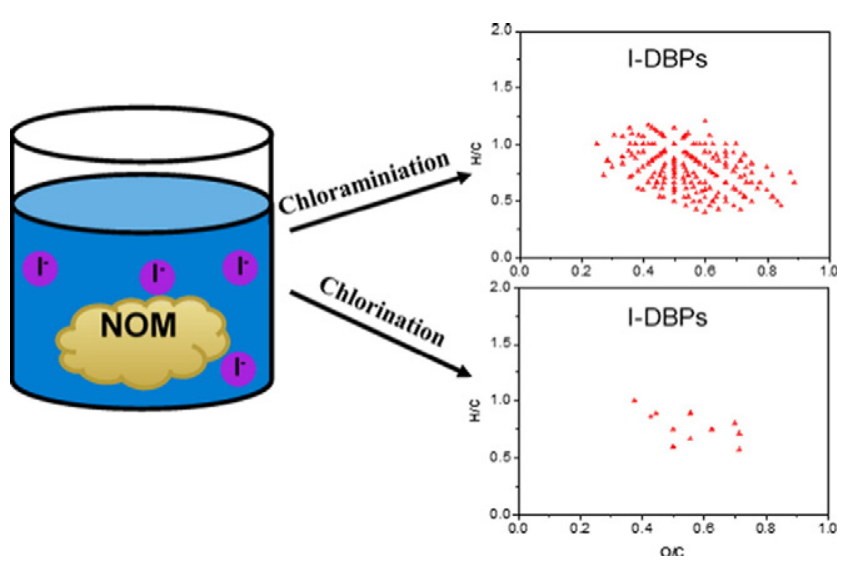

A B S T R A C T

Iodinated disinfection byproducts (I-DBPs), formed from the reaction of disinfectant(s) with organic matter in the presence of iodide in raw water, have recently been focused because of their more cytotoxic and genotoxic properties than their chlorinated or brominated analogues. To date, only a few I-DBPs in drinking water have been identified. In this study, C18 solid phase extraction coupled with electrospray ionization ultrahigh resolution Fourier transform ion cyclotron resonance mass spectrometry (ESI FT-ICR MS) was used to characterize unknown I-DBPs in chloraminated/chlorinated water spiked with iodide and humic substances. In total, 178 formulas for one-iodine-containing products, 13 formulas for two-iodine-containing products, and 15 formulas for one-chlorine and one-iodine-containing products were detected in the chloraminated water sample, while only 9 formulas for one-iodine-containing products and 6 formulas for one-chlorine and one-iodine-containing products were found in the chlorinated water sample. Most I-DBPs have corresponding chlorine-containing analogues with identical $\mathrm{CHO}$ compositions. As indicated by the modified aromaticity index ( $\left.\mathrm{AI}_{\text {mod }}\right)$, in the $\mathrm{C} 18$ extracts, more than $68 \%$ of the I-DBPs have aromatic structures or polycyclic aromatic structures. This result demonstrates that the use of chloramination as an alternative disinfection method may lead to the formation

\footnotetext{
* Corresponding author at: State Key Laboratory of Environmental Aquatic Chemistry, Research Center for Eco-Environmental Sciences, Chinese Academy of Sciences, P. O. Box 2871, Beijing 100085, China.

E-mail address: yangmin@rcees.ac.cn (M. Yang).
} 
of abundant species of I-DBPs in the presence of iodide. Thus, the suitability of adopting chloramination as an alternative disinfection method should be reevaluated, particularly when iodide is present in raw water.

(c) 2016 Elsevier B.V. All rights reserved.

\section{Introduction}

Formation of iodinated disinfection byproducts (I-DBPs) including iodine containing trihalomethanes (THMs) and iodinated acetic acids during disinfection of drinking water has recently caused wide attention because they exhibit greatly increased toxicological effects compared to their chlorinated and brominated analogues (Plewa et al., 2004; Cemeli et al., 2006; Richardson et al., 2007; Plewa et al., 2008; Richardson et al., 2008). Mammalian cell assay has shown that iodoacetic acid is 3 and 288 times more cytotoxic, and 2 and 47 times more genotoxic than bromoacetic acid and chloroacetic acid, respectively (Plewa et al., 2004). Most recently, it has been reported that I-DBPs present significantly higher developmental toxicity and growth inhibition than their brominated or chlorinated DBP analogues (Yang and Zhang, 2013; Liu and Zhang, 2014). Yang et al. (2014) investigated toxic impact of bromide and iodide on drinking water disinfection and found that both cytotoxicity and genotoxicity were correlated with total organic iodine (TOI), but not to total organic chlorine (TOCl). Therefore, the potential health impacts of the I-DBPs could not be neglected.

Richardson et al. (2006) surveyed over 100 distribution systems and found the presence of I-THMs in one plant with a concentration as high as $25 \mu \mathrm{g} / \mathrm{L}$. At the same time, five iodinated acids, including iodoacetic acid, bromoiodoacetic acid, 3-bromo-3-iodopropenoic acid, and 2iodo-3-methylbutenedioic acid, have been identified in drinking water disinfected with chloramine during a nationwide DBP occurrence study in the U.S. (Plewa et al., 2004; Krasner et al., 2006). These iodinated acids were also found in most drinking water samples in a 23-city DBPs occurrence study conducted in the U.S. and Canada, and the maximum concentration for iodoacetic acid was $1.7 \mu \mathrm{g} / \mathrm{L}$ (Richardson et al., 2008).

Several studies have investigated the formation and occurrence of IDBPs during chlorination and chloramination, a substitution of chlorination to reduce the formation of the regulated THMs and haloacetic acids (HAAs), of iodide containing water samples (Karpel Vel Leitner et al., 1998; Bichsel and von Gunten, 1999, 2000; Hua and Reckhow, 2007; Ding and Zhang, 2009). It was found that chloramination favors the formation of I-DBPs because chloramines can oxidize $\mathrm{I}^{-}$to $\mathrm{HOI}$ but without formation of iodate $\left(\mathrm{IO}_{3}^{-}\right)$, which is an inert and non-toxic form of iodine (Bichsel and von Gunten, 1999, 2000). However, partially due to lack of appropriate analytical method for I-DBPs, most of these studies use iodine containing trihalomethanes (I-THMs) or the group parameter, total organic iodine (TOI) as the representative of the whole pool of IDBPs. Considering the potential health effect of I-DBPs are directly depending on their molecule structures, it is necessary to extensively characterize and compare the molecular species of I-DBPs formed with different disinfectants.

To date, only a few I-DBPs have been identified by gas chromatography/mass spectrometry (GC/MS) (Richardson et al., 2007; Plewa et al., 2008; Richardson et al., 2008). However, recent studies have shown that a significant portion of unknown halogen containing DBPs would be polar/highly polar (Zhang et al., 2008; Ding and Zhang, 2009; Zhang et al., 2012a; Zhang et al., 2014). Ding and Zhang (2009) have successfully identified 17 polar/highly polar I-DBPs using the precursor ion scan (PIS) method via electrospray ionization-triple quadrupole mass spectrometry (ESI-tqMS). However, the unit mass resolution of tqMS is still too low to allow nominally isobaric ions to be massresolved and may bias the compositional interpretation of I-DBPs. Recently, ultrahigh resolution Fourier transform ion cyclotron resonance mass spectrometry (FT-ICR MS) has been successfully used to characterize the previously unknown Cl-DBPs and Br-DBPs (Zhang et al., 2012a;
Zhang et al., 2012b; Lavonen et al., 2013; Zhang et al., 2014). The ultrahigh resolution and mass accuracy of FT-ICR MS combined with electrospray ionization (ESI) allows the determination of unambiguous and exact molecular formulas (Stenson et al., 2003; Kim et al., 2006a, 2006b; Hertkorn et al., 2008). It is thus anticipated that the ESI FT-ICR MS method could also be suitable for identifying the molecular formulas of unknown I-DBPs.

The main objective of this study was to characterize unknown IDBPs in chlorinated/chloraminated water spiked with iodide and humic substances by using ESI FT-ICR MS. In addition, the species pattern of unknown I-DBPs was compared with that of Cl-DBPs formed during chlorination or chloramination to reveal the effect of different disinfectants on the formation of I-DBPs.

\section{Materials and methods}

\subsection{Materials}

Suwannee River fulvic acid (SRFA) was obtained from the International Humic Substances Society. Methanol (LC-MS grade) was purchased from Merck (Darmstadt, Germany). Formic acid (99\%) was purchased from Acros. Sodium hypochlorite solution (analytical grade, Sinopharm Chemical Reagent, Beijing) was diluted and used to prepare free chlorine. Ammonium chloride (p.a. grade) was obtained from Sinopharm Chemical Reagent (Beijing). Ultrapure water with a resistivity of $18.2 \mathrm{M} \Omega \cdot \mathrm{cm}^{-1}$ was obtained from a Milli-Q purification system (Millipore, USA).

\subsection{Simulated drinking water sample preparation}

Simulated drinking water samples were prepared with ultrapure water containing $3.0 \mathrm{mg} / \mathrm{L} \mathrm{SRFA}$ as C, $90.0 \mathrm{mg} / \mathrm{L} \mathrm{NaHCO}$, and $200 \mu \mathrm{g} / \mathrm{L}$ potassium iodide as $\mathrm{I}^{-}$, according to Ding and Zhang (2009). A relatively high iodide concentration $(200 \mu \mathrm{g} / \mathrm{L})$ was used to amplify iodinated DBPs so that unknown iodinated DBPs could be detected and identified by the FTICR MS method. For chlorination, 1-L water samples were chlorinated in sealed 1-L amber glass bottles with a chlorine dose of $5.0 \mathrm{mg} / \mathrm{L}$ as $\mathrm{Cl}_{2}$. For chloramination, 1-L water samples were chloraminated in sealed 1-L amber glass bottles with $5.0 \mathrm{mg} / \mathrm{L}$ monochloramine (as $\mathrm{Cl}_{2}$ ). Monochloramine was prepared just before use by reacting ammonium chloride and sodium hypochlorite solutions in a chlorine-to-ammonia ratio of $0.8 \mathrm{~mol} / \mathrm{mol}$. All the samples were kept in darkness at $20^{\circ} \mathrm{C}$. The reaction was halted 5 days later by the addition of excess $\mathrm{Na}_{2} \mathrm{~S}_{2} \mathrm{O}_{3}$.

To determine whether there were any impurities in the reagents or any artifacts in the disinfection and subsequent pretreatment, SRFA control samples were generated by repeating the same procedure with samples of the aforementioned simulated water without chlorination or chloramination and chlorination/chloramination control samples were generated by repeating the same chlorination/chloramination procedure with simulated water samples without potassium iodide. Information of simulated drinking water sample composition and treatment applied are provided in Table 1.

\subsection{Pretreatment of simulated drinking water samples}

Procedures for water sample pretreatment were carried out according to previous studies (Zhang et al., 2012a). Briefly, 1-L water samples were adjusted to $\mathrm{pH} 2.0$ with formic acid and pumped through a Seppak $\mathrm{C}_{18}$ solid-phase extraction (SPE) cartridge $(1 \mathrm{~g}, 6 \mathrm{~mL}$, Waters, USA) at a flow rate of $\sim 5 \mathrm{~mL} / \mathrm{min}$. The SPE cartridge was activated and 
Table 1

Simulated drinking water sample composition and treatment applied.

\begin{tabular}{|c|c|c|c|}
\hline Sample name & Components & Disinfection & SPE \\
\hline SRFA control & $3.0 \mathrm{mg} / \mathrm{L} \mathrm{SRFA}$ as C, $90.0 \mathrm{mg} / \mathrm{L} \mathrm{NaHCO}{ }_{3}$, and $200 \mu \mathrm{g} / \mathrm{L}$ potassium iodide as $\mathrm{I}^{-}$ & Not applied & Applied \\
\hline $\mathrm{SRFA}+\mathrm{NaClO}$ & $3.0 \mathrm{mg} / \mathrm{L}$ SRFA as C, $90.0 \mathrm{mg} / \mathrm{L} \mathrm{NaHCO} 3$ & Chlorination & Applied \\
\hline $\mathrm{SRFA}+\mathrm{NH}_{2} \mathrm{Cl}$ & $3.0 \mathrm{mg} / \mathrm{L}$ SRFA as $\mathrm{C}, 90.0 \mathrm{mg} / \mathrm{L} \mathrm{NaHCO}{ }_{3}$ & Chloramination & Applied \\
\hline $\mathrm{SRFA}+\mathrm{I}+\mathrm{NaClO}$ & $3.0 \mathrm{mg} / \mathrm{L} \mathrm{SRFA}$ as C, $90.0 \mathrm{mg} / \mathrm{L} \mathrm{NaHCO}{ }_{3}$, and $200 \mu \mathrm{g} / \mathrm{L}$ potassium iodide as $\mathrm{I}^{-}$ & Chlorination & Applied \\
\hline $\mathrm{SRFA}+\mathrm{I}+\mathrm{NH}_{2} \mathrm{Cl}$ & $3.0 \mathrm{mg} / \mathrm{L} \mathrm{SRFA}$ as $\mathrm{C}, 90.0 \mathrm{mg} / \mathrm{L} \mathrm{NaHCO}{ }_{3}$, and $200 \mu \mathrm{g} / \mathrm{L}$ potassium iodide as $\mathrm{I}^{-}$ & Chloramination & Applied \\
\hline
\end{tabular}

conditioned with methanol and acidified ultrapure water. For complete removal of inorganic ions, the cartridge was rinsed with $10 \mathrm{~mL}$ acidified ultrapure water before elution. After extraction, the cartridge was dried under high-purity grade nitrogen gas and eluted with $10 \mathrm{~mL}$ of methanol. A concentration factor of 100 was achieved for water samples before further analysis.

\subsection{FT-ICR MS}

The ultra-high resolution mass spectrometry analyses were performed using a Bruker apex ultra 9.4 T FT-ICR MS interfaced with negative ion mode electrospray ionization (ESI-). Sample extract was dissolved in methanol and injected into the electrospray source at $3 \mu \mathrm{L} / \mathrm{min}$ using a syringe pump. The operating conditions for ESIconsisted of a $4.0 \mathrm{kV}$ emitter voltage, $4.5 \mathrm{kV}$ capillary column introduce voltage, and $-320 \mathrm{~V}$ capillary column end voltage. The mass range was set to $m / z 150-800$. The data size was set to $4 \mathrm{M}$ words, and 256 scans were acquired for each spectrum.

The FT-ICR mass spectrometer was externally calibrated for a mass range of 150-800 using a sodium formate aqueous solution (Zhang et al., 2012a; Zhang et al., 2014). The acquired spectra were internally recalibrated with a known homologous series of the SRFA sample (Zhang et al., 2012a; Zhang et al., 2014). After internal calibration, mass accuracy of $<1 \mathrm{ppm}$ was achieved. Molecular formulas were assigned from the $m / z$ peaks by a custom-developed mass calculator program (Zhang et al., 2012a) limited to the following chemical elements: ${ }^{12} \mathrm{C}_{0-100},{ }^{13} \mathrm{C}_{0-2},{ }^{1} \mathrm{H}_{0-200},{ }^{14} \mathrm{~N}_{0-3},{ }^{16} \mathrm{O}_{0-30},{ }^{32} \mathrm{~S}_{0-2},{ }^{35} \mathrm{Cl}_{0-4},{ }^{37} \mathrm{Cl}_{0-2}$ and ${ }^{127} \mathrm{I}_{0-2}$ atoms. All assigned formulas must meet the following criteria: (1) mass accuracy $<0.5 \mathrm{ppm}$; (2) the sum of $\mathrm{H}$ and halogen $(\mathrm{Cl}, \mathrm{I})$ atoms must be at least $1 / 3$ the number of $C$ atoms and cannot exceed $2 \mathrm{C}+\mathrm{N}+2$; (3) the sum of $\mathrm{H}$, halogen and $\mathrm{N}$ atoms must be even (the "nitrogen rule"); and (4) the number of $\mathrm{N}$ or $\mathrm{O}$ atoms cannot exceed the number of $C$ atoms (Zhang et al., 2014). These criteria ensure that formulas were assigned at a high level of confidence and can at least chemically exist.

\subsection{Limitations}

In this study, solid phase extraction (SPE) was used to extract complex mixtures of DBPs, as pointed in previous studies (Zhang et al., 2012a; Zhang et al., 2014), only C18 extractable DBP molecules were analyzed by mass spectrometry. In addition, the mass range was set to $\mathrm{m} / \mathrm{z}$ $150-800$. Therefore, this study mainly characterized the $C_{18}$ extractable DBP molecules and the detected formulas do not represent the entire pool of I-DBPs formed after chlorination/chloramination.

\section{Results and discussion}

\subsection{Detection of unknown I-DBPS}

Fig. 1 exemplarily shows the detection of unknown Cl-DBPs and IDBPs at the nominal mass $m / z 403$ in simulated drinking water samples after chlorination and chloramination. Newly formed one-iodinecontaining DBPs and two iodine-containing DBPs were clearly observed in the mass spectrum of the SRFA $+\mathrm{I}+\mathrm{NH}_{2} \mathrm{Cl}$ sample (Fig. 1e). The IDBPs were observed at almost every odd nominal mass from $\mathrm{m} / \mathrm{z} 247$
499 in the SRFA $+\mathrm{I}+\mathrm{NH}_{2} \mathrm{Cl}$ sample, and occasionally observed in the $\mathrm{SRFA}+\mathrm{I}+\mathrm{NaClO}$ sample. The very high mass accuracy $(<0.5 \mathrm{ppm})$ in combination with ultrahigh resolution of the FT-ICR MS allowed us to assign exact molecular formulas for the newly formed I-DBPs. In total, molecular formulas of 178 peaks containing one iodine, 13 peaks containing two iodine and 15 peaks containing one chlorine and one iodine were identified in the SRFA $+\mathrm{I}+\mathrm{NH}_{2} \mathrm{Cl}$ sample, while only 9 peaks containing one iodine and 6 peaks containing one chlorine and one iodine were identified in the SRFA $+\mathrm{I}+\mathrm{NaClO}$ sample. All of the iodine containing formulas detected in the SRFA $+\mathrm{I}+\mathrm{NaClO}$ sample were also found in the SRFA $+\mathrm{I}+\mathrm{NH}_{2} \mathrm{Cl}$ sample.

Recently, Ding and Zhang (2009) have developed the precursor ion scan (PIS) method using electrospray ionization-triple quadrupole mass spectrometry (ESI-tqMS) for fast selective detection of polar/highly polar iodinated DBPs, and characterized 17 polar/highly polar I-DBPs in chloraminated simulated drinking water. Only 3 formulas of I-DBPs identified in this study were also found in the study by Ding and Zhang (2009). The other 203 formulas of I-DBPs are for the first time reported.

\subsection{Pattern of I-DBPS}

Molecular formulas of I-DBPs can be analyzed using Kendrick plot with $z^{*}$ value, in which homologous series of molecules could be easily identified. The $z^{*}$ (Eq. (1)) value has been shown to be a useful parameter for presorting homologous series of fulvic acids (Hsu et al., 1992; Stenson et al., 2003; Reemtsma and These, 2005). In Eq. (1), the modulus is the remainder of the division of nominal mass (NM) by 14 . Presorting based on $\mathrm{z}^{*}$ ensures that molecules assigned to the same homologous series (differing only in the number of $\mathrm{CH}_{2}$ groups) differ from each other in mass by $14 \mathrm{Da}$, because molecules that differ from each other by multiples of 14 will have the same $z^{*}$ value. Fig. 2 shows the Kendrick plot of formulas of I-DBPs detected in the SRFA+I+ $\mathrm{NH}_{2} \mathrm{Cl}$ sample. Similar to previous findings for $\mathrm{Cl}$-DBPs and $\mathrm{Br}$-DBPs, the iodine-containing formulas can be sorted out into homologous series, suggesting they may arise from homologous series of parent NOM components.

$\mathrm{Z} *=(\operatorname{modulus}[\mathrm{NM} / 14])-14$

The van Krevelen diagram is another widely used tool for visualizing FT-ICR MS data (van Krevelen, 1950; Schmidt et al., 2009; Ohno et al., 2010). In a van Krevelen diagram, individual molecular formulas are plotted based on their elemental ratios of hydrogen to carbon $(\mathrm{H} / \mathrm{C})$ and oxygen to carbon $(\mathrm{O} / \mathrm{C})$. The specific $\mathrm{H} / \mathrm{C}$ and $\mathrm{O} / \mathrm{C}$ ratios for each molecular formula align and fall at a certain point on the diagram, allowing evaluation of relative hydrogen deficiency or oxygen deficiency of the molecular formulas. Fig. 3 shows the van Krevelen diagram of the I-DBPs detected in the SRFA $+\mathrm{I}+\mathrm{NH}_{2} \mathrm{Cl}$ sample. The $\mathrm{H} / \mathrm{C}$ ratios of these iodinated DBPs were lower than 1.2 . The relatively low $\mathrm{H} / \mathrm{C}$ ratios suggest relatively high degree of unsaturation and the presence of aromatic structures in the molecules of I-DBPs. A modified aromaticity index $\left(\mathrm{AI}_{\mathrm{mod}}\right)$, which is a suitable parameter for the identification of aromatic and polycyclic structures in NOM from ultrahigh resolution mass spectrometry data, was calculated from the molecular formulas according to Koch and Dittmar (2006) to estimate the fraction of aromatic 


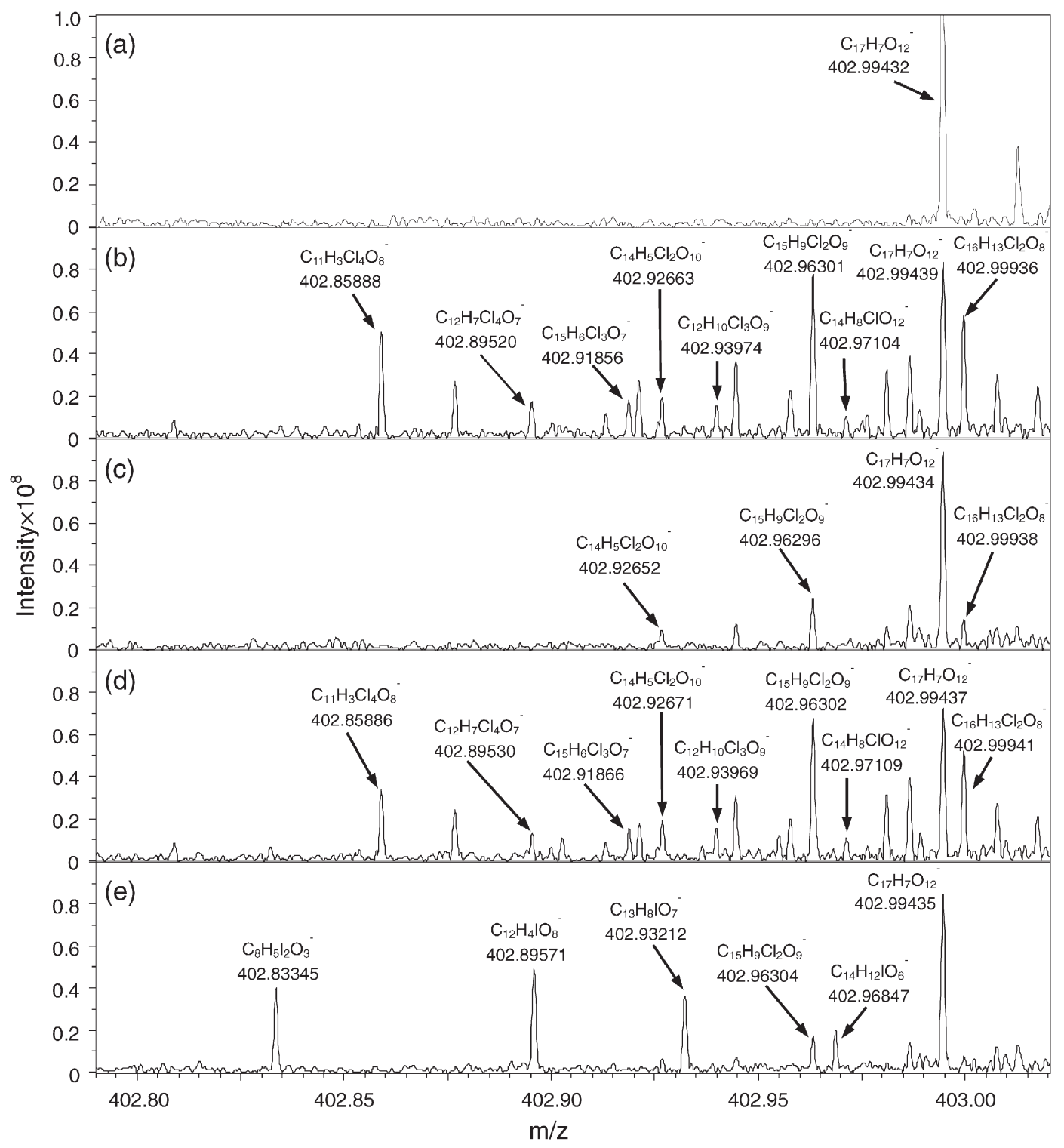

Fig. 1. Negative-ion ESI FT-ICR mass spectra for iodine-containing products at nominal mass 403. (a) SRFA control sample, (b) SRFA+NaClO sample, (c) $\mathrm{SRFA}+\mathrm{NH}{ }_{2} \mathrm{Cl}$ sample, (d) SRFA+I+NaClO sample, and (e) SRFA+I $+\mathrm{NH}_{2} \mathrm{Cl}$ sample.

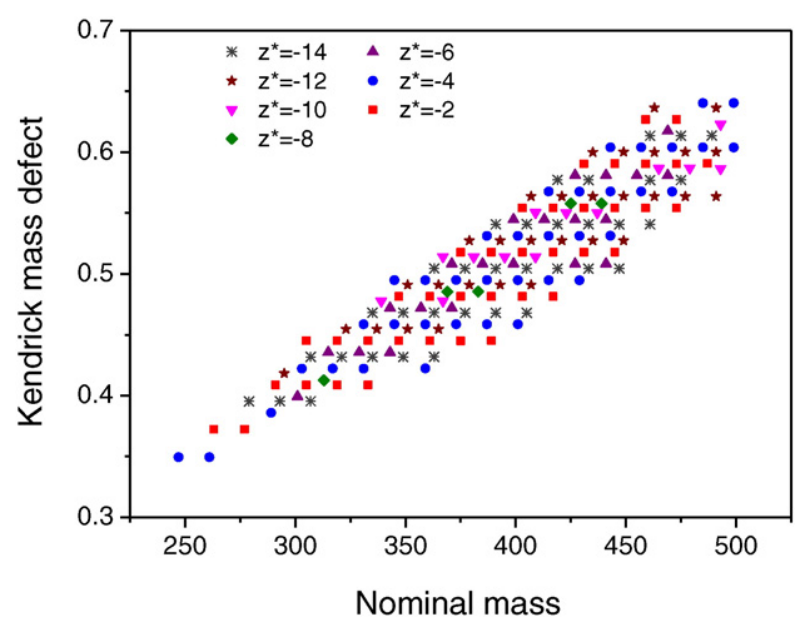

Fig. 2. Kendrick mass defect analysis with $z^{*}$ of one iodine-containing formulas in $\mathrm{SRFA}+\mathrm{I}+\mathrm{NH}_{2} \mathrm{Cl}$ sample.

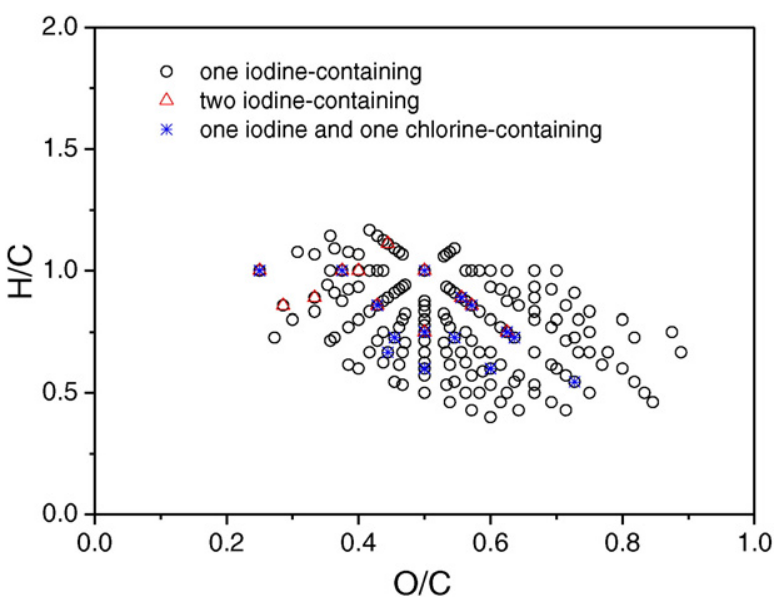

Fig. 3. van Krevelen diagram of iodine-containing formulas identified in SRFA+I+N $\mathrm{NH}_{2} \mathrm{Cl}$ sample. 
$\left(0.5<\mathrm{AI}_{\text {mod }}<0.67\right)$ and polycyclic aromatic structures $\left(0.67 \leq \mathrm{AI}_{\text {mod }}\right)$. The $\mathrm{Al}_{\text {mod }}$ was calculated according to Eq. (2), in which $\mathrm{nC}, \mathrm{nO}, \mathrm{nH}$, $\mathrm{nCl}$ and $\mathrm{nI}$ are the numbers of carbon, oxygen, hydrogen, chlorine, and iodine atoms in the molecular formula. Among the 206 I-DBPs detected in the C18 extracts, 96 of them ( 47\%) have aromatic structures and 44 of them ( 21\%) have polycyclic aromatic structures. Recent studies have demonstrated that aromatic I-DBPs are an important category of I-DBPs in chloramine-disinfected water (Pan et al., 2016a; Pan et al., 2016b; Gong et al., 2016). More importantly, recent evidence has shown that aromatic I-DBPs generally are substantially more developmentally toxic than aliphatic I-DBPs (Pan et al., 2016a). Thus more attention should be paid to the aromatic I-DBPs, which might form during chloramination of iodide containing source water.

$\mathrm{AI}_{\text {mod }}=\frac{1+\mathrm{nC}-0.5 \times \mathrm{nO}-0.5 \times \mathrm{nH}-0.5 \times \mathrm{nCl}-0.5 \times \mathrm{nI}}{\mathrm{nC}-0.5 \times \mathrm{nO}}$

\subsection{Comparison of patterns of I-DBPs with those of Cl-DBPs}

Previous study has shown that most polar Br-DBPs formed during chlorination have corresponding chlorine-containing analogues, which have identical CHO compositions (Zhang et al., 2014). In this study, all 206 I-DBPs identified in the SRFA $+\mathrm{I}+\mathrm{NH}_{2} \mathrm{Cl}$ sample were compared to the chlorinated components identified in the same sample and the SRFA $+\mathrm{NH}_{2} \mathrm{Cl}$ sample. In total, 380 formulas of one chlorine-containing components, 112 formulas of two chlorine-containing components, and 5 formulas of three chlorine-containing components were identified in the SRFA+I+ $\mathrm{NH}_{2} \mathrm{Cl}$ sample, while a little more chlorinecontaining components were identified in the SRFA $+\mathrm{NH}_{2} \mathrm{Cl}$ sample (438 formulas of one chlorine-containing components, 156 formulas of two chlorine-containing components, and 3 formulas of threechlorine-containing components) (Table 2). Among the 178 one iodine-containing DBPs, 158 of them have corresponding onechlorine-containing analogues. Three of the 13 two-iodine-containing DBPs have corresponding two chlorine-containing analogues. Fig. 4a shows the van Krevelen diagram of I-DBPs and the Cl-DBPs identified in the chloramination samples. Compared to the Cl-DBPs, the I-DBPs cluster in an area with a relatively low $\mathrm{H} / \mathrm{C}$ value (0.4-1.2). In addition, compared to the I-DBPs, 144 of the Cl-DBPs (29\%) have aromatic structures and 65 of the Cl-DBPs (13\%) have polycyclic aromatic structures. Fig. 4b compares I-DBPs and Cl-DBPs using the carbon number against $\mathrm{AI}_{\text {mod }}$ plot. The carbon numbers of I-DBPs range from 7 to 18 , while the carbon numbers of Cl-DBPs range from 8 to 23. It is interesting that, compared to Cl-DBPs, I-DBPs cluster in the upper left of the plot with relatively high $\mathrm{AI}_{\text {mod }}(0.35-0.8)$. This finding suggested that precursor molecules with high aromaticity might prefer to form I-DBPs.

\subsection{Comparison of DBPs patterns in chlorination/chloramination}

Previous studies have shown that both chlorine and chloramine can oxidize $\mathrm{I}^{-}$rapidly to $\mathrm{HOI}$, but the half-life of HOI during chloramination is much longer than that during chlorination, leading to the formation of more I-DBPs during chloramination (Bichsel and von Gunten, 2000; Krasner et al., 2006; Hua and Reckhow, 2007). In this study the number and peak intensities of I-DBPs in the SRFA $+\mathrm{I}+\mathrm{NH}_{2} \mathrm{Cl}$ sample were

Table 2

Number of DBPs detected in different samples.

\begin{tabular}{|c|c|c|c|c|c|c|c|}
\hline \multirow[t]{2}{*}{ Sample } & \multicolumn{7}{|c|}{ Number of DBPs } \\
\hline & $1 \mathrm{Cl}$ & $2 \mathrm{Cl}$ & $3 \mathrm{Cl}$ & $4 \mathrm{Cl}$ & 1I & 2I & $1 \mathrm{Cl}+1 \mathrm{I}$ \\
\hline $\mathrm{SRFA}+\mathrm{NaClO}$ & 673 & 488 & 186 & 70 & 0 & 0 & 0 \\
\hline $\mathrm{SRFA}+\mathrm{NH}_{2} \mathrm{Cl}$ & 438 & 156 & 3 & 0 & 0 & 0 & 0 \\
\hline $\mathrm{SRFA}+\mathrm{I}+\mathrm{NaClO}$ & 646 & 451 & 167 & 50 & 9 & 0 & 6 \\
\hline $\mathrm{SRFA}+\mathrm{I}+\mathrm{NH}_{2} \mathrm{Cl}$ & 380 & 112 & 5 & 0 & 178 & 13 & 15 \\
\hline
\end{tabular}
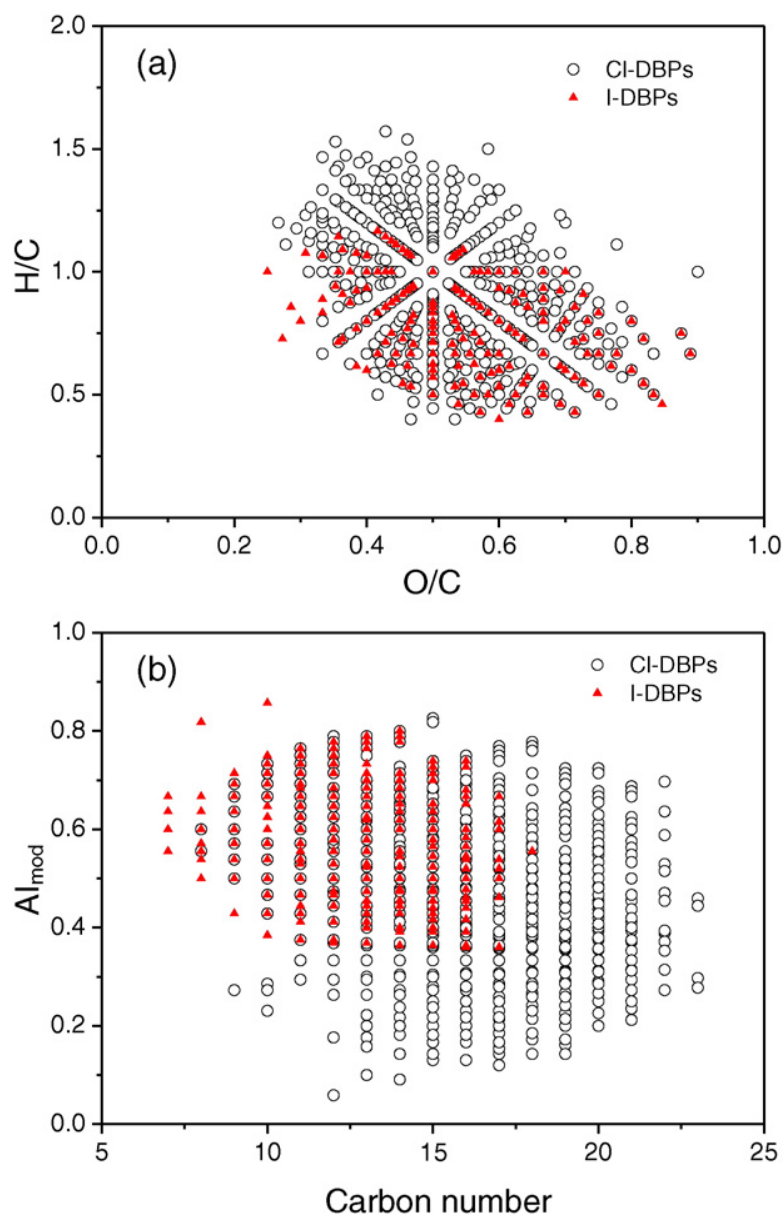

Fig. 4. van Krevelen diagram (a) and $\mathrm{AI}_{\text {mod }}$ against carbon number plot (b) of iodinecontaining formulas identified in the SRFA $+\mathrm{I}+\mathrm{NH}_{2} \mathrm{Cl}$ sample and chlorine-containing formulas identified in the SRFA $+\mathrm{NH}_{2} \mathrm{Cl}$ sample.

significantly greater than those in the SRFA $+\mathrm{I}+\mathrm{NaClO}$ sample. Compared to 206 I-DBPs detected in the SRFA $+\mathrm{I}+\mathrm{NH}_{2} \mathrm{Cl}$ sample, only 15 IDBPs were found in the SRFA+I+NaClO sample. Both chlorine and monochloramine can oxidize $\mathrm{I}^{-}$to $\mathrm{HOI}$, which can react with NOM to form I-DBPs. During chlorination, $\mathrm{HOCl} / \mathrm{OCl}^{-}$can further oxidize $\mathrm{HOI}$ to $\mathrm{IO}_{3}^{-}$, which is stable and unreactive toward NOM, with a reaction rate constant of 8.2-52 $\mathrm{M}^{-1} \mathrm{~s}^{-1}$ (Bichsel and von Gunten, 1999). The reaction rate constant of monochloramine and HOI is smaller than $2 \times 10^{-3} \mathrm{M}^{-1} \mathrm{~s}^{-1}$ (Bichsel and von Gunten, 1999), whereas the reaction rate constant of HOI and NOM is $0.1-0.4 \mathrm{M}^{-1} \mathrm{~s}^{-1}$ (Bichsel and von Gunten, 2000). This means that the half-life of HOI during chloramination is much longer than that during chlorination, resulting in the formation of more I-DBPs during chloramination than during chlorination (Bichsel and von Gunten, 2000; Krasner et al., 2006; Hua and Reckhow, 2007; Ding and Zhang, 2009). Chloramination has been frequently used as alternative to chlorination to reduce the formation of the regulated THMs and HAAs. The above results demonstrated that chloramination may not be a good choice for treating iodide containing source water.

Although I-DBPs were mainly observed in chloramination sample, lots of Cl-DBPs were found in both chloramination and chlorination samples. Table 2 shows number of DBPs identified in chlorination and chloramination samples. In total, 646 formulas of one-chlorinecontaining components, 451 formulas of two-chlorine-containing components, 167 formulas of three-chlorine-containing components and 50 formulas of four-chlorine-containing components were identified in the SRFA+I+NaClO sample. 673 formulas of one-chlorine-containing components, 488 formulas of two-chlorine-containing components, 186 
formulas of three-chlorine-containing components and 70 formulas of four-chlorine-containing components were identified in the $\mathrm{SRFA}+\mathrm{NaClO}$ sample. When comparing the formulas of $\mathrm{Cl}-\mathrm{DBPs}$ found in the SRFA $+\mathrm{NH}_{2} \mathrm{Cl}$ sample and the SRFA $+\mathrm{NaClO}$ sample, it was found that $99 \%$ of the formulas with one chlorine and $100 \%$ of the formulas with two or three chlorine found in the SRFA $+\mathrm{NH}_{2} \mathrm{Cl}$ sample were also detected in the SRFA+ NaClO sample. A similar overlap in formulas of Cl-DBPs was also observed between the SRFA $+\mathrm{I}+\mathrm{NH}_{2} \mathrm{Cl}$ sample and the SRFA $+\mathrm{I}+\mathrm{NaClO}$ sample (99\% for one chlorine containing formulas and $100 \%$ for two or three chlorine containing formulas found in SRFA $+\mathrm{I}+\mathrm{NH}_{2} \mathrm{Cl}$ sample).

\section{Conclusions}

In this study, 206 formulas of previously unknown polar I-DBPs were identified in chlorinated/chloraminated simulated drinking water. Species of I-DBP formed during chloramination (206 formulas) were much more than that formed during chlorination (15 formulas). More than $68 \%$ of the 206 formulas of I-DBPs detected in the C18 extracts have aromatic structures or polycyclic aromatic structures, indicating precursor molecules with high aromaticity might be more reactive and preferential to form I-DBPs during chloramination of iodide-containing water. The results reported here provide valuable information on occurrence of I-DBPs and may help us in minimizing and controlling I-DBPs during drinking water disinfection.

\section{Acknowledgments}

This work was supported by the National Natural Science Foundation of China (Nos. 21377150 and 51578530).

\section{Appendix A. Supplementary data}

All assigned formulas for I-DBPs and Cl-DBPs are available in a spreadsheet file in the supplementary data. Supplementary data associated with this article can be found in the online version, at http://dx.doi. org/10.1016/j.scitotenv.2016.02.157.

\section{References}

Bichsel, Y., von Gunten, U., 1999. Oxidation of iodide and hypoiodous acid in the disinfection of natural waters. Environ. Sci. Technol. 33 (22), 4040-4045.

Bichsel, Y., von Gunten, U., 2000. Formation of iodo-trihalomethanes during disinfection and oxidation of iodide containing waters. Environ. Sci. Technol. 34 (13), 2784-2791.

Cemeli, E., Wagner, E.D., Anderson, D., Richardson, S.D., Plewa, M.J., 2006. Modulation of the cytotoxicity and genotoxicity of the drinking water disinfection byproduct iodoacetic acid by suppressors of oxidative stress. Environ. Sci. Technol. 40 (6), 1878-1883.

Ding, G., Zhang, X., 2009. A picture of polar iodinated disinfection byproducts in drinking water by (UPLC/)ESI-tqMS. Environ. Sci. Technol. 43 (24), 9287-9293.

Gong, T., Zhang, X., Li, Y., Xian, Q., 2016. Formation and toxicity of halogenated disinfection byproducts resulting from linear alkylbenzene sulfonates. Chemosphere 149 70-75.

Hertkorn, N., Frommberger, M., Witt, M., Koch, B.P., Schmitt-Kopplin, Ph., Perdue, E.M., 2008. Natural organic matter and the event horizon of mass spectrometry. Anal. Chem. 80 (23), 8908-8919.

Hsu, C.S., Qian, K., Chen, Y.C., 1992. An innovative approach to data analysis in hydrocarbon characterization by on-line liquid chromatography-mass spectrometry. Anal. Chim. Acta 264 (1), 79-89.

Hua, G., Reckhow, D.A., 2007. Comparison of disinfection byproduct formation from chlorine and alternative disinfectants. Water Res. 41 (8), 1667-1678.

Karpel Vel Leitner, N., Vessella, J., Dore, M., Legube, B., 1998. Chlorination and formation of organoiodinated compounds: the important role of ammonia. Environ. Sci. Technol. 32 (11), 1680-1685.

Kim, S., Rodgers, R.P., Marshall, A.G., 2006a. Truly "exact" mass: elemental composition can be determined uniquely from molecular mass measurement at similar to
$0.1 \mathrm{mDa}$ accuracy for molecules up to similar to $500 \mathrm{Da}$. Int. J. Mass Spectrom. 251 (2-3), 260-265.

Kim, S., Kaplan, L.A., Hatcher, P.G., 2006b. Biodegradable dissolved organic matter in a temperate and a tropical stream determined from ultra-high resolution mass spectrometry. Limnol. Oceanogr. 51 (2), 1054-1063.

Koch, B.P., Dittmar, T., 2006. From mass to structure: an aromaticity index for highresolution mass data of natural organic matter. Rapid Commun. Mass Spectrom. 20 (5), 926-932.

Krasner, S.W., Weinberg, H.S., Richardson, S.D., Pastor, S.J., Chinn, R., Sclimenti, M.J., Onstad, G.D., Thruston Jr., A.D., 2006. Occurrence of a new generation of disinfection byproducts. Environ. Sci. Technol. 40 (23), 7175-7185.

Lavonen, E.E., Gonsior, M., Tranvik, L.J., Schmitt-Kopplin, P., Koehler, S.J., 2013. Selective chlorination of natural organic matter: identification of previously unknown disinfection byproducts. Environ. Sci. Technol. 47 (5), 2264-2271.

Liu, J., Zhang, X., 2014. Comparative toxicity of new halophenolic DBPs in chlorinated saline wastewater effluents against a marine alga: halophenolic DBPs are generally more toxic than haloaliphatic ones. Water Res. 65, 64-72.

Ohno, T., He, Z., Sleighter, R., Honeycutt, C.W., Hatcher, P.G., 2010. Ultra high resolution mass spectrometry and indicator species analysis to identify marker components of soil- and plant biomass-derived organic matter fractions. Environ. Sci. Technol. 44 (22), 8594-8600.

Pan, Y., Li, W., An, H., Cui, H., Wang, Y., 2016a. Formation and occurrence of new polar iodinated disinfection byproducts in drinking water. Chemosphere 144, 2312-2320.

Pan, Y., Zhang, X., Li, Y., 2016b. Identification, toxicity and control of iodinated disinfection byproducts in cooking with simulated chlor(am)inated tap water and iodized table salt. Water Res. 88, 60-68.

Plewa, M.J., Wagner, E.D., Richardson, S.D., Thruston Jr., A.D., Woo, Y.T., Mckague, A.B., 2004. Chemical and biological characterization of newly discovered iodoacid drinking water disinfection byproducts. Environ. Sci. Technol. 38 (18), 4713-4722.

Plewa, M.J., Muellner, M.G., Richardson, S.D., Fasano, F., Buettner, K.M., Woo, Y.T. Mckague, A.B., Wagner, E.D., 2008. Occurrence, synthesis, and mammalian cell cytotoxicity and genotoxicity of haloacetamides: an emerging class of nitrogenous drinking water disinfection byproducts. Environ. Sci. Technol. 42 (3), 955-961.

Reemtsma, T., These, A., 2005. Comparative investigation of low-molecular-weight fulvic acids of different origin by SEC-Q-TOF-MS: new insights into structure and formation. Environ. Sci. Technol. 39 (10), 3507-3512.

Richardson, S.D., Ellington, J.J., Crumley, F.G., Evans, J.J., Plewa, M.J., Wagner, E.D., 2006 Occurrence of iodo-acid DBPs in US chloraminated drinking waters. Abstr. Pap. Am. Chem. Soc. 231 (33-ENVR).

Richardson, S.D., Plewa, M.J., Wagner, E.D., Schoeny, R., DeMarini, D.M., 2007. Occurrence, genotoxicity, and carcinogenicity of regulated and emerging disinfection byproducts in drinking water: a review and roadmap for research. Mutat. Res. 636 (1-3) $178-242$.

Richardson, S.D., Fasano, F., Ellington, J.J., Crumley, F.G., Buettner, K.M., Evans, J.J., Blount, B.C., Silva, L.K., Waite, T.J., Luther, G.W., Mckague, A.B., Miltner, R.J., Wagner, E.D., Plewa, M.J., 2008. Occurrence and mammalian cell toxicity of iodinated disinfection byproducts in drinking water. Environ. Sci. Technol. 42 (22), 8330-8338.

Schmidt, F., Elvert, M., Koch, B.P., Witt, M., Hinrichs, K., 2009. Molecular characterization of dissolved organic matter in pore water of continental shelf sediments. Geochim. Cosmochim. Acta 73 (11), 3337-3358.

Stenson, A.C., Marshall, A.G., Cooper, W.T., 2003. Exact masses and chemical formulas of individual Suwannee river fulvic acids from ultrahigh resolution electrospray ionization Fourier transform ion cyclotron resonance mass spectra. Anal. Chem. 75 (6), 1275-1284.

van Krevelen, D.W., 1950. Graphical statistical method for the study of structure and reaction processes of coal. Fuel 19, 269-284.

Yang, M., Zhang, X., 2013. Comparative developmental toxicity of new aromatic halogenated DBPs in a chlorinated saline sewage effluent to the marine polychaete Platynereis dumerilii. Environ. Sci. Technol. 47 (19), 10868-10876.

Yang, Y., Komaki, Y., Kimura, S.Y., Hu, H., Wagner, E.D., Marinas, B.J., Plewa, M.J., 2014 Toxic impact of bromide and iodide on drinking water disinfected with chlorine or chloramines. Environ. Sci. Technol. 48 (20), 12362-12369.

Zhang, X.R., Talley, J.W., Boggess, B., Ding, G.Y., Birdsell, D., 2008. Fast selective detection of polar brominated disinfection byproducts in drinking water using precursor ion scans. Environ. Sci. Technol. 42 (17), 6598-6603.

Zhang, H., Zhang, Y., Shi, Q., Hu, J., Chu, M., Yu, J., Yang, M., 2012a. Study on transformation of natural organic matter in source water during chlorination and its chlorinated products using ultrahigh resolution mass spectrometry. Environ. Sci. Technol. 46 (8), 4396-4402.

Zhang, H., Zhang, Y., Shi, Q., Ren, S., Yu, J., Ji, F., Luo, W., Yang, M., 2012b. Characterization of low molecular weight dissolved natural organic matter along the treatment trait of a waterworks using Fourier transform ion cyclotron resonance mass spectrometry. Water Res. 46 (16), 5197-5204.

Zhang, H., Zhang, Y., Shi, Q., Zheng, H., Yang, M., 2014. Characterization of unknown brominated disinfection byproducts during chlorination using ultrahigh resolution mass spectrometry. Environ. Sci. Technol. 48 (6), 4396-4402. 